\title{
Neuroprotective effects of Clitoria ternatea L. against propionic acid-induced behavior and memory impairment in autistic rat model
}

\author{
K. N. Jiji and P. Muralidharan* (1)
}

\begin{abstract}
Background: Autism spectrum disorder is primarily characterized by complex behavioral and altered memory as a consequence of neuronal development abnormalities. The treatment of autism is highly challenging because of the lack of knowledge about its exact etiopathology. In the Ayurvedic system of medicine, there are group of plants named 'Medhya drugs' because of their ability to improve brain- and neuron-related activities like learning and memory. Clitoria ternatea $\mathrm{L}$. is one of the listed 'Medhya drugs' which have been proved for its memory enhancement effects; in the present study, the ethanolic root extract of Clitoria ternatea L. was evaluated for its neuroprotective ability against propionic acid-induced memory and behavior impairments in an autistic rat model. The variation in behavior and memory were investigated by utilizing different procedures like rat elevated plus maze and novel object recognition test. In vitro assays for the estimations of glutamate and serotonin were also performed in isolated rat brain tissue homogenate.
\end{abstract}

Results: The object recognition and elevated plus maze test were showed the promising effects of Clitoria ternatea $\mathrm{L}$. ethanolic root extract against the propionic acid-induced autism. In this study, the propionic acid infused rats (Group II) fail to recognize and explore the novel object compared to Group I (infused with phosphate-buffered saline) animals; extract treatment at two different doses $(250 \mathrm{mg} / \mathrm{kg}$ and $500 \mathrm{mg} / \mathrm{kg}$ ) (Groups III \& IV, respectively) prevented these damage significantly $(p<0.001)$ so that extract-treated groups showed significant improvement in novel object recognition in a dose-dependent manner. Similarly, the effect of extract treatment on learning and memory of rats was investigated using transfer latency as a parameter for acquisition and retention of memory process on elevated plus maze; this further proved the memory enhancement ability of Clitoria ternatea L. Extract treatment also significantly reduced the concentration of different neurotransmitters like serotonin and glutamate in rat brain homogenate (Groups III \&IV) in a dose-dependent manner as compared with the Group II.

Conclusion: The ethanolic root extract of Clitoria ternatea L. proved to be effective against propionic acid-induced memory and behavior impairments in an autistic rat model.

Keywords: Clitoria ternatea, ASD, Neurotransmitters

*Correspondence: clbmpharmacology@hotmail.com Department of Pharmacology, C.L. Baid Metha College of Pharmacy, Affiliated to Tamil Nadu Dr. M.G.R Medical University, Chennai 600097, India

\section{Background}

Autism spectrum disorder (ASD) is a neurodevelopmental disorder characterized by complex behavioral impairments that can be devastating for affected individuals, their families, and society. The individuals affected with ASD are manifested with symptoms like deviations in social relations, narrow or monotonous interests, diminishing in verbal and non-verbal communication, and 
purposeless motor behavior [1]. ASD prevalence estimation by Center for Disease Control and Prevention (CDC) in 2018 reported that there is a 15 percent increase in the ASD prevalence in USA to 1 in 59 children, from 1 in 68 in 2016 [2]. The exact pathophysiology of autism is still a mystery but research evidence pointing out the factors such as genetics, neural, environmental, and immunology have prominent role on ASD pathology [3, 4].

Neurodevelopmental defects harm various brain functions. Neurotransmitters play an important role in the normal development of the brain and also adequate levels each neurotransmitter are mandatory for maintaining functions such as learning and memory, motor-behavior activity in normal ways $[5,6]$.

Autism is not completely curable, preventable not even fully manageable with the help of the present treatment system because of poor available knowledge on its cause, pathophysiology, and due to its heterogeneous symptoms. Current synthetic drug therapy tries to improve memory, learning ability, and also trying to calm the patients, but all the drugs used for this purpose are having their profile of serious adverse effects. At this juncture, research has to be done incorporating various systems of medicine, especially the Ayurvedic system to identify the most relevant pathogenesis also to obtain a good cure or preventive medicine for autism. In the Ayurvedic system of medicine 'Medhya drugs'-a group of herbal medicines-are known for their actions on the nervous system [7]. These 'Medhya drugs' mentioned in Ayurvedic texts are said to improve mental abilities like learning and memory enhancement, antidepressant effect, also effective in preventing mood fluctuating disorders [8]. So these drugs can be screened against autism animal models to evaluate their efficacy and safety. Clitoria ternatea $\mathrm{L}$. is one of the listed 'Medhya drugs' [9]; in our present study, we have evaluated the neuroprotective effects of ethanolic extract of Clitoria ternatea $\mathrm{L}$ against propionic acid (PPA) induced memory and behavioral impairments.

\section{Methods}

\section{Chemicals}

Propionic acid and neurotransmitters estimation kits (Glutamate Assay Colorimetric kit, Serotonin ELISA kit) were purchased from Sigma-Aldrich-Merck, Bengaluru, India, and supplied by Southern India Scientific Corporation, Kandanchavadi, Chennai, India, whereas all other chemicals and reagent were of analytical grade.

\section{Experimental animals}

Healthy Wistar male rats between 4 and 8 weeks of age and weighing about 150-180 gm were used for the study. Animals were purchased from the animal house of Tamil
Nadu Veterinary and Animal Sciences University, Chennai. They were housed in polypropylene cages at a temperature of $25-30^{\circ} \mathrm{C}$ and relative humidity $35-45 \%$, light and dark cycles of 12 and $12 \mathrm{~h}$, respectively, for one week before and during the experiments. Animals were provided with free access to a standard rodent pellet diet and water ad libitum. All animal studies were performed after getting the approval from the 'Institutional animal ethical committee with an approved reference number'; also possible measures were taken to minimize the suffering of the animals.

\section{Collection and Preparation of Clitoria ternatea L. root extract}

Fresh roots of Clitoria ternatea L were collected, authentified, shade-dried at room temperature to remove moisture, and then coarsely powdered by using an electric grinder. The powdered materials were stored in an airtight container and used for further extraction.

\section{Extraction procedure}

Extraction of roots of Clitoria ternatea L. was carried out using ethanol by hot continuous extraction method with Soxhlet apparatus. The extract obtained was collected and concentrated by gentle heating followed by using rotarat vacuum evaporator. The concentrated extract was then weighed, calculated the percentage yield, and stored. The extract was subjected to various preliminary phytochemicals tests [10].

\section{Experimental design}

A total of twenty-four rats were utilized for the study. Before starting the study procedure, all the rats were undergone a surgical procedure for cannula implantation. After 14 days of the surgery, the rats were stratified in to four separate groups containing six Wistar rats each.

Group I: Received vehicle alone per oral (p.o) (1\% Tween-80 solution).

Group II: Received vehicle alone p.o (1\% Tween-80 solution).

Group III: Received ethanolic extract of Clitoria ternatea L.(EECT) [11] at dose of $\mathbf{2 5 0} \mathbf{~ m g / k g}$-suspended in $1 \%$ Tween-80 solution p.o.,

Group IV: Received ethanolic extract of Clitoria terna-

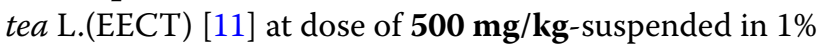
Tween-80 solution p.o.,

The vehicles and the extract were administered orally using an intragastric tube daily for 28 days. After 21 days of extract administration, each group of animals except Group I received intracerebroventricular (ICV) infusions of propionic acid (PPA) $(4.0 \mu \mathrm{l}$ of a $0.26 \mathrm{M}$ solution PPA was dissolved in phosphate-buffered saline (PBS) vehicle) daily for 7 consecutive days (between 22nd and 28th 


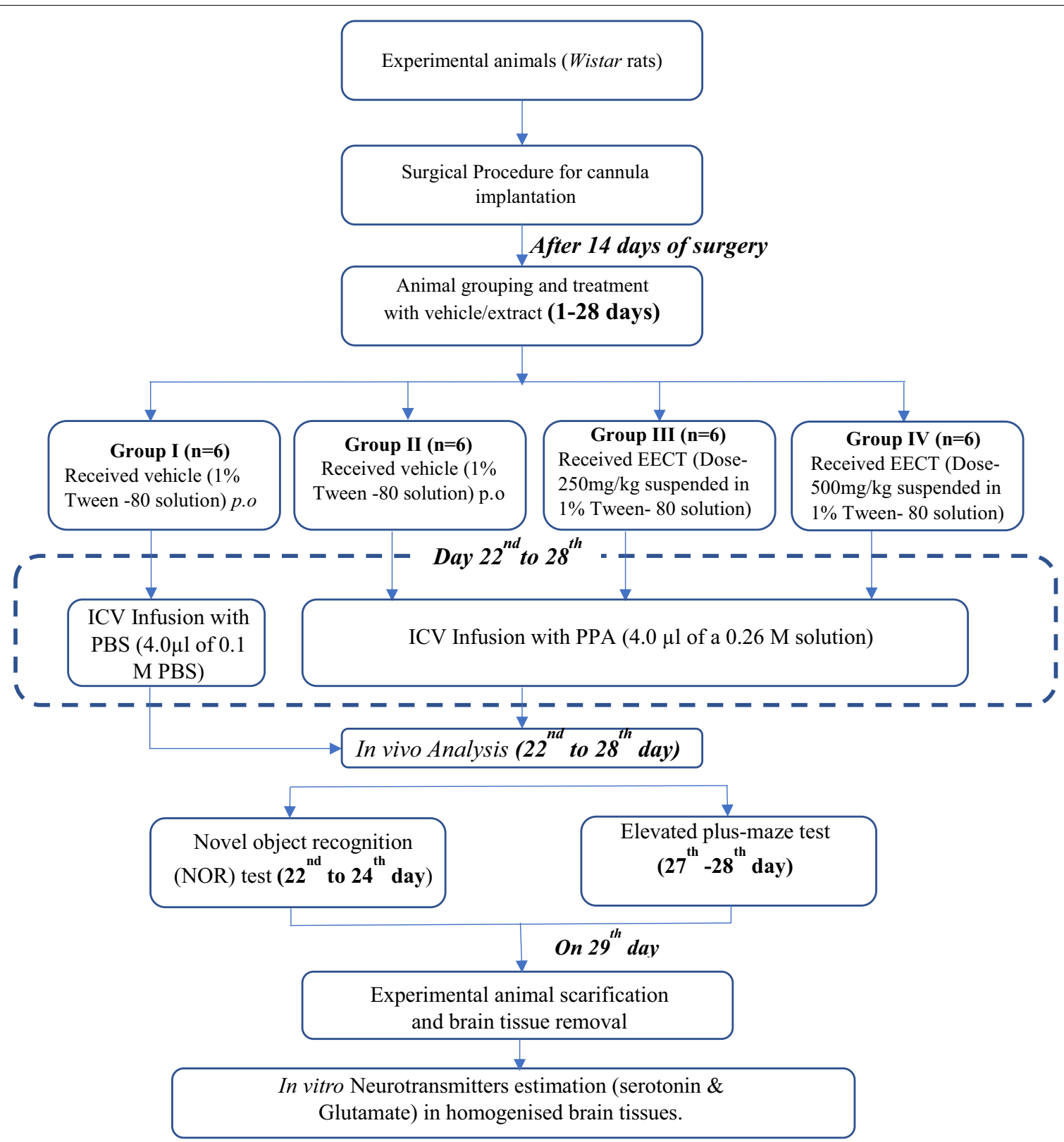

EECT - Ethanolic extract of Clitoria ternatea L., p.o- Per oral, ICV - Intracerebroventricular, PBS- Phosphate-buffered saline, PPA- Propionic acid

Fig. 1 Schematic diagram of the experimental design

days). Group I rats received ICV infusions PBS $(4.0 \mu \mathrm{l}$ of 0.1 M PBS) between 22nd and 28th days.

A schematic representation of the experimental design is provided in Fig. 1.

\section{Induction of ASD}

Surgical procedures for cannula implantation

Surgical procedures were completed under aseptic conditions. All rats were implanted with a 23gauge (ga) guide cannula using standard stereotaxic techniques. Before surgery, each rat was treated with atropine methyl nitrate (0.1 ml Subcutaneous injection). Before placing the stereotaxic apparatus, rats were anesthetized using inhaled isoflurane and 3\% oxygen. During surgery, body temperature was maintained normal using a heating pad.

The tip of the guide cannula was placed in such a way that it will penetrate into the brain lateral ventricle just below the border of corpus callosum. For proper infusion 
into lateral ventricle below the tip of the guide cannula, another 30ga injection cannula is placed so that the tip of injection cannula was further protruded $0.5 \mathrm{~mm}$ deepar. Each cannula was provided with an obturator closing, which can be removed before each intracerebroventricular (ICV) infusion. A Sage syringe pump with sterile PE10 tubing was attached with 30ga injection cannula for the purpose of infusion. Small screws were placed in the top of the skull, and the cannula was affixed to the skull with dental acrylic. Oral extract/vehicle administration began approximately 14 days after surgery $[4,12]$.

\section{Intracerebroventricular (ICV) infusion procedure}

Prior to the ICV infusion of propionic acid (PPA), it was dissolved in appropriate vehicle. Phosphate-buffered saline (PBS) was used as vehicle which was buffered to $\mathrm{pH} 7.5$ by means of concentrated hydrochloric acid and sodium hydroxide. All the animals except Group I received ICV infusions of PPA $(4.0 \mu \mathrm{l}$ of a $0.26 \mathrm{M}$ solution) and the Group I rats received ICV infusions PBS
(4.0 $\mu \mathrm{l}$ of $0.1 \mathrm{M} \mathrm{PBS})$. The infusions were given for 7 consecutive days (between 22nd and 28th days) in twice daily manner. The infusion duration was about $60 \mathrm{~s}$, but an additional $60 \mathrm{~s}$ was allowed for the infusion cannula to remain in the position before being removed. Assessment of habituation behavior and memory assessments were done on each specific day (day 22 to day 28) following the infusion of PPA. Habituation behavior assessment was screened by performing a 'novel object recognition test', and memory evaluation was done using 'elevated plus maze' $[4,12]$. The effects of PPA infusion and the effectiveness of the extract to prevent those effects were evaluated by performing a comparative statistical analysis with the results obtained for each group by carrying out both in vivo test-novel object recognition test and elevated plus maze test.

\section{Novel object recognition (NOR) test}

This experiment took placed in a square open enclosure of $50 \times 50 \mathrm{~cm}^{2}$, surrounded by four walls of $50 \mathrm{~cm}^{2}$

Table 1 Effect of EECT on identical object recognition

\begin{tabular}{|c|c|c|c|c|}
\hline \multirow[t]{2}{*}{ S.no } & \multirow[t]{2}{*}{ Groups } & \multirow[t]{2}{*}{ Treatment given } & \multicolumn{2}{|c|}{ Time of Exploration of Object (seconds) } \\
\hline & & & $\begin{array}{l}\text { Object } A 1 \text { (time } \\
\text { in seconds) }\end{array}$ & Object A2 (time in seconds) \\
\hline 1 & Group I & Vehicle (1\% Tween -80 solution) per oral + ICV infusion of PBS & $21.33 \pm 7.31 \mathrm{~ns}$ & $32 \pm 5.76^{* * * *}$ \\
\hline 2 & Group \| & Vehicle (1\% Tween -80 solution) per oral + ICV infusion of PPA & $14.5 \pm 4.51$ & $14.67 \pm 5.89$ \\
\hline 3 & Group III & $\begin{array}{l}\text { EECT-dose } 250 \mathrm{mg} / \mathrm{kg} \text {-suspended in } 1 \% \text { Tween- } 80 \text { solution per oral } \\
+ \text { ICV infusion of PPA }\end{array}$ & $23.83 \pm 3.71^{*}$ & $25.83 \pm 6.37^{* *}$ \\
\hline 4 & Group IV & $\begin{array}{l}\text { EECT-dose } \mathbf{5 0 0} \mathbf{~} \mathbf{~ g} \mathbf{g} \mathbf{k g} \text {-suspended in } 1 \% \text { Tween- } 80 \text { solution per oral + } \\
\text { ICV infusion of PPA }\end{array}$ & $35.5 \pm 7.97^{* * * *}$ & $34.66667 \pm 3.83^{* * * *}$ \\
\hline
\end{tabular}

Values are represented in Mean \pm SD (Standard deviation), $n=6$ (6 rats in each group)

Comparison: Group II vs Group I, Group II vs Group III, and Group II vs Group IV

ns nonsignificant

${ }^{*} p<0.05,{ }^{* *} p<0.01,{ }^{* * *} p<0.001,{ }^{* * * *} p<0.0001$

Table 2 Effect of EECT on novel object recognition

\begin{tabular}{|c|c|c|c|c|}
\hline \multirow[t]{2}{*}{ S. no } & \multirow[t]{2}{*}{ Groups } & \multirow[t]{2}{*}{ Treatment given } & \multicolumn{2}{|c|}{ Time of exploration of object (seconds) } \\
\hline & & & $\begin{array}{l}\text { Object } A \text { (time in } \\
\text { seconds) }\end{array}$ & $\begin{array}{l}\text { Object B novel } \\
\text { object (time in } \\
\text { seconds) }\end{array}$ \\
\hline 1 & Group I & Vehicle (1\% Tween -80 solution) per oral + ICV infusion of PBS & $22.5 \pm 5.24^{*}$ & $54.33 \pm 7.90^{* * * *}$ \\
\hline 2 & Group II & Vehicle (1\% Tween -80 solution) per oral + ICV infusion of PPA & $15.33 \pm 4.27$ & $14.5 \pm 4.76$ \\
\hline 3 & Group III & $\begin{array}{l}\text { EECT-dose } 250 \mathrm{mg} / \mathrm{kg} \text {-suspended in } 1 \% \text { Tween- } 80 \text { solution per } \\
\text { oral + ICV infusion of PPA }\end{array}$ & $20.67 \pm 2.42 \mathrm{~ns}$ & $36.67 \pm 4.23^{* * * *}$ \\
\hline 4 & Group IV & $\begin{array}{l}\text { EECT-dose } 500 \mathrm{mg} / \mathrm{kg} \text {-suspended in } 1 \% \text { Tween- } 80 \text { solution per } \\
\text { oral }+ \text { ICV infusion of PPA }\end{array}$ & $16 \pm 4.73 \mathrm{~ns}$ & $46.17 \pm 9.79^{* * * *}$ \\
\hline
\end{tabular}

Values are represented in Mean \pm SD (Standard deviation), $n=6$ ( 6 rats in each group)

Comparison: Group II vs Group I, Group II vs Group III, and Group II vs Group IV

ns nonsignificant

${ }^{*} p<0.05,{ }^{* *} p<0.01,{ }^{* * *} p<0.001,{ }^{* * * *} p<0.0001$ 


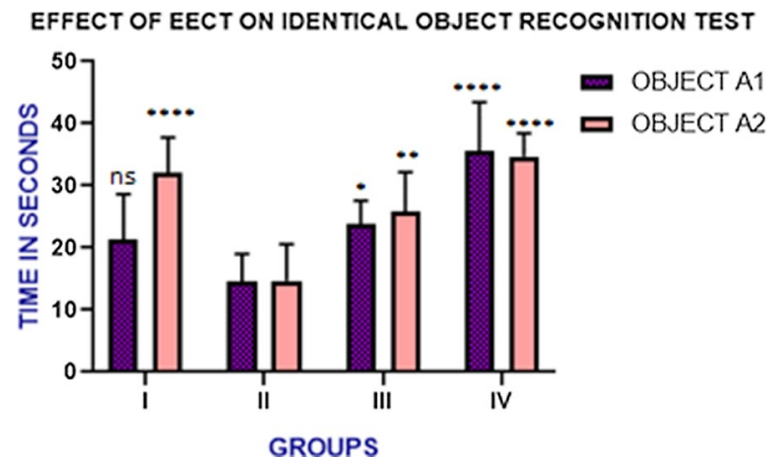

Fig. 2 Effect of EECT on identical object recognition

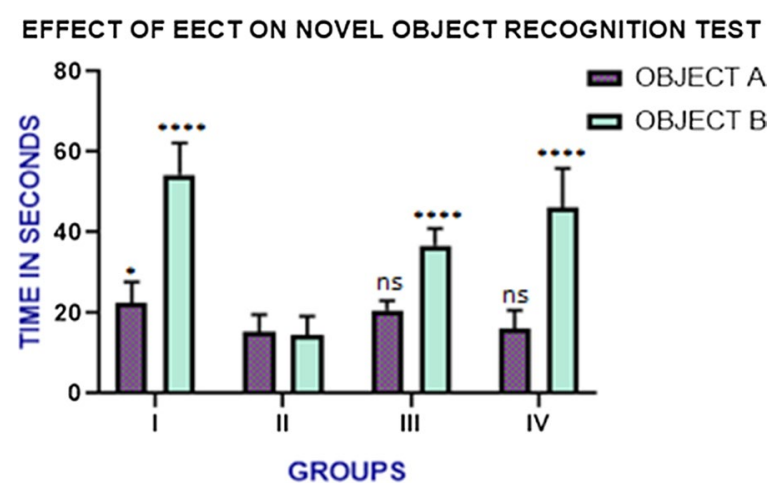

Fig. 3 Effect of EECT on novel object recognition

elevation. At the beginning of the test, each rat was allowed to liberally explore the device for $5 \mathrm{~min}$ in the absence of any object. Twenty-four hours later, the animals have explored two matching objects (A1 and A2) positioned at the two adjacent corners of the device at $10 \mathrm{~cm}$ from the walls, for $5 \mathrm{~min}$; this was the 'acquisition' session. Exploration was only called when the rat had a nose directed fewer than one $\mathrm{cm}$ to the object while nibbling and marking were not measured exploration. After a postponement of $24 \mathrm{~h}$, the rats were again positioned in the device, but this time, one of the two identical objects was replaced by another entirely different (B). The animal is permitted to explore the two different objects for $5 \min [13,14]$.

The state of memory was calculated by the following equation:

Recognition index =time spent in discovering the object $B$

/Sigma time spent exploring objects A and B [13].

\section{Elevated plus maze}

The memory power of the rodents can be investigated efficiently by using an elevated plus maze. Rat elevated plus maze is specified with a central platform $(10 \mathrm{~cm} \times 10 \mathrm{~cm})$ associated with two open arms $(50 \mathrm{~cm} \times 10 \mathrm{~cm})$ and two enclosed arms $(50 \mathrm{~cm} \times 40 \mathrm{~cm} \times 10 \mathrm{~cm})$ [15]. An elevation of $50 \mathrm{~cm}$ height from the floor was provided while positioning the maze. On the sixth day of propionic acid administration, the experiments were carried out to record the 'transfer latency (TL)' in seconds [15]. This was considered as a training session for each rat; before returning to its home cage rats were permitted to explore the maze for an extra $2 \mathrm{~min}$. After $24 \mathrm{~h}$ (i.e., the seventh day of PPA infusion/28th day of the extract administration), each of the rats was examined for their retention memory $[15,16]$.

On the 8th day (29th day of the study), animals were killed by ethically approved euthanasia method-cervical dislocation, and brain tissues extracted and homogenized using a tissue homogenizer, and it was preserved /stored at $-80^{\circ} \mathrm{C}$ for further analysis of neurotransmitters like serotonin [17] and glutamate [18].

\section{Statistical analysis}

Statistical validation of the data was done with the help of computer software GraphPad Prism version 8; statistical

Table 3 Effect of EECT on elevated plus maze

\begin{tabular}{|c|c|c|c|c|}
\hline S. no & Groups & Treatment given & $\begin{array}{l}\text { Transfer latency (time } \\
\text { in seconds) }\end{array}$ & $\begin{array}{l}\text { Retention latency } \\
\text { (time in seconds) }\end{array}$ \\
\hline 1 & Group I & Vehicle (1\% Tween -80 solution) per oral + ICV infusion of PBS & $48 \pm 4^{* *}$ & $18 \pm 4.52^{* * * *}$ \\
\hline 2 & Group $\|$ & Vehicle (1\% Tween -80 solution) per oral + ICV infusion of PPA & $59.5 \pm 2.88$ & $57 \pm 6.48$ \\
\hline 3 & Group III & $\begin{array}{l}\text { EECT-dose } 250 \mathrm{mg} / \mathrm{kg} \text {-suspended in } 1 \% \text { Tween- } 80 \text { solution per } \\
\text { oral + ICV infusion of PPA }\end{array}$ & $49.67 \pm 6.31^{* *}$ & $37.83 \pm 10.41^{* * *}$ \\
\hline 4 & Group IV & $\begin{array}{l}\text { EECT-dose } 500 \mathrm{mg} / \mathrm{kg} \text {-suspended in } 1 \% \text { Tween- } 80 \text { solution per } \\
\text { oral + ICV infusion of PPA }\end{array}$ & $51 \pm 6.23^{*}$ & $22.17 \pm 8.13^{* * * *}$ \\
\hline
\end{tabular}

Values are represented in Mean \pm SD (standard deviation), $n=6$ (6 rats in each group)

Comparison: Group II vs Group I, Group II vs Group III, and Group II vs Group IV

ns nonsignificant

${ }^{*} p<0.05,{ }^{* *} p<0.01,{ }^{* * *} p<0.001,{ }^{* * * *} p<0.0001$ 


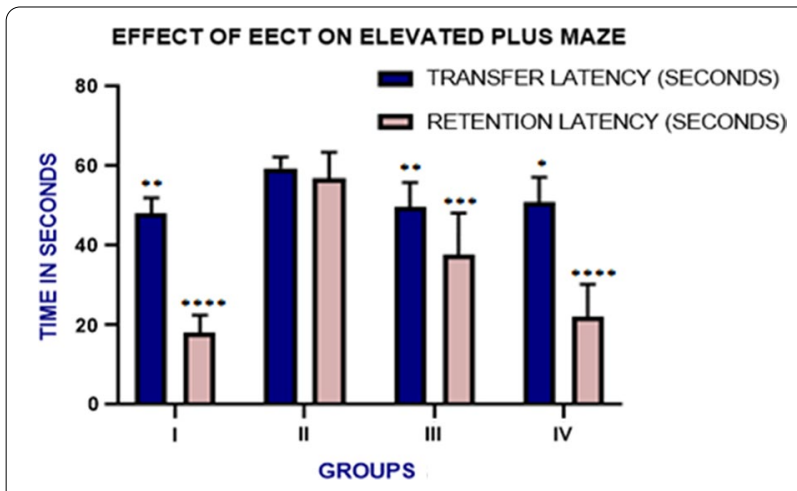

Fig. 4 Effect of EECT on elevated plus maze

test utilized was ANOVA, followed by Dunnett's multiple

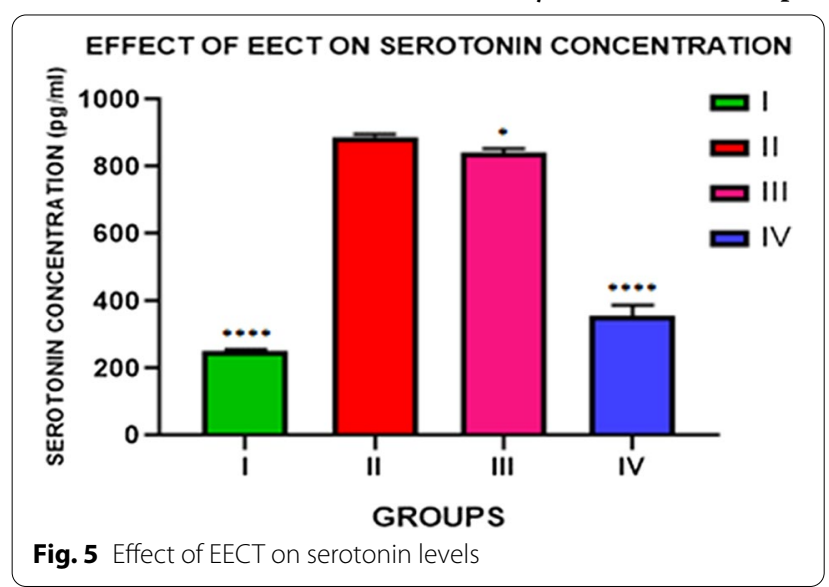

comparison test.

All the values in the tabular column represent the Mean \pm SD (Standard deviation), $n=6$ (6 rats in each group).

\section{Results}

Assessment of habituation behavior

Effect of EECT on NOR test

NOR test is a normally used behavioral assay to investigate different aspects of learning and memory in rodents. This test was completed by 3 days: day 1 -habituation day, day 2-training day, and day 3- testing day. Recognition memory of rats is its innate preference for novelty (novel object) evaluated by carrying out the NOR task. In the present study, the Group II rats showed least exploring tendency toward the identical and novel objects when compared with Groups I, III, and IV. The results obtained are given in Tables 1 , 2 and represented in Figs. 2 and 3. Results pointing toward the dose-dependent effects of EECT and levels of statistical significance are more for the Group IV rats as compared with the Group III.

\section{Assessment of memory and retention Effect of EECT on elevated plus maze task}

Evaluation of working memory of rats was done by using this task. There was a significant reduction in retention latency in Group II animals when compared with Groups I, III, and IV implicating the declined cognitive skills of the Group II rats because of the PPA infusion. EECT treatment significantly improved the cognitive skills in a dose-dependent manner. The results obtained are given in Table 3 and represented in Fig. 4.

\section{Effects on various neurotransmitters levels Effect of EECT on serotonin levels}

Altered 5-HT (5-Hydroxy tryptamine) system in brain is one of the key findings associated with ASD. The study results showed an increased concentration of serotonin in the brain tissue homogenates of Group II rats as compared with Group I animals. The EECT treatment at two dose levels 250 and $500 \mathrm{mg} / \mathrm{kg}$ (Groups III and IV, respectively) exhibited a significant $(p<0.05$ and $p<0.0001)$ decrease in the level of brain serotonin in comparison with Group II animals. Results obtained are picturized in Fig. 5.

\section{Effect of EECT on glutamate levels}

Glutamate is one of the excitatory neurotransmitters well known for its prominent role in memory and cognitive skill development in humans/animals. PPA infusion in Group II rats produced an increased concentration of glutamate in brain as compared with Group I rats. The EECT treatment at two dose levels 250 and $500 \mathrm{mg} / \mathrm{kg}$ (Groups III and IV, respectively) exhibited a significant ( $p<0.0001$ for both the groups) decrease in the level of brain glutamate in comparison with Group II animals. Results obtained are picturized in Fig. 6.

\section{Discussion}

ASD is one of the leading neurocognitive disorders characterized by behavior and memory impairments. Common symptoms associated with ASD include diminished language and communication skills, repetitive or restrictive interests, stereotyped behaviors and movements, sensory disturbances, hyperactivity, and self-injury [19]. A complementary or alternative system of medicine is a reliable option in the treatment of ASD, as its cause or pathophysiology is not exactly known. Acceptability of medicinal plant origin drugs is increasing day by day because of its low cost and reduced toxicity profile. The present study indicates the neuroprotective effect of 


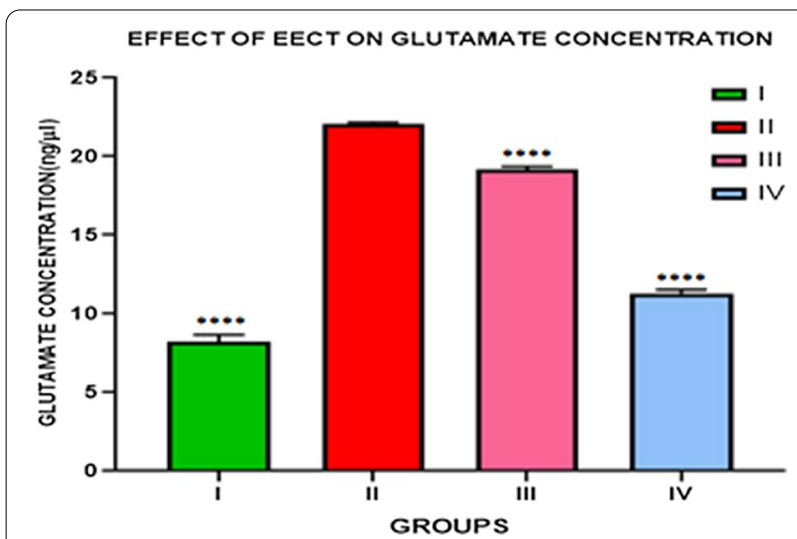

Fig. 6 Effect of EECT on glutamate concentration

ethanolic extract of Clitoria ternatea. $\mathrm{L}$ in propionic acid (PPA)-induced autism model in rats.

PPA is a metabolic intermediate of fatty acid metabolism [20] and also an end-product of enteric bacterial fermentation [21, 22]. The major application of PPA is in food industry as food preservative in wheat and dairy food products [23]. Many studies reported that repeated microinfusions of PPA into the lateral cerebral ventricles of adult rats produced behavioral, electrophysiological, and neuropathological effects comparable with ASD [2426]. Because of this evidence, we had to choose the PPA $\mathrm{ICV}$ infusion as an inducing technique to produce ASD in rats.

Elevated plus maze was utilized to investigate the effects of plant extract in the rat acquisition and retention memory formation process. The evaluation was based on the transfer latency (TL); the results provided a piece of evidence for the utility of shortened TL on secondday trial in rats as a parameter (retention latency-RL) for retention or consolidation of memory [27] while the Group II animals do not show any improvement in RL, but EECT-treated groups showed significant improvement in RL in a dose-dependent manner. The results implicate the memory enhancement property of Clitoria ternatea $\mathrm{L}$.

Habituation behavior and recognition and remembrance of rats were analyzed by carrying out the NOR task. The recognition of novelty indicates the degree of animal's cognitive skills which is primarily mediated by brain perirhinal cortex. The basic concept of the classical NOR task is when animals are allowed to explore a known and a novel object, frequency, and duration of exploring time for the unique object used to be more than the familiar one [28]. The fondness for a unique object demonstrates that the appearance of the known object subsists in the animal's memory. The utility of the NOR task can be extended from short-term memory evaluation to long-term memory evaluation of rodents by manipulating the retention period [29]. The recognition memory formation is mainly led by perirhinal cortex and hippocampus of the brain, so any damage to these areas will lead to the compromised performance in NOR task [30]. In this study, the PPA-infused rats (Group II) failed to recognize and explore the provided novel object compared with the Group I animals; this may due to the damage of brain structures like hippocampal and cortex because of PPA-ICV infusion; EECT treatment prevented this damage so that EECT-treated groups showed significant improvement in novel object recognition in a dose-dependent manner.

Raised whole-brain serotonin is the first biomarker identified in ASD [31]. It is believed that in human body the serotonin plays a vital role in regulating mood, sleep, hunger, and sociability. It can also stimulate the intestinal muscles involved in digestion, helping for the contraction and expansion of the blood vessels, and in brain it conveys messages between neurons [32]. Serotonin functions drastically vary in infants and in adults; in infants it helps in the formation of neurons, synapse, and translocation of formed neurons to their correct locations, but in adult's brain it mainly acts as a neurotransmitter to communicate messages between neurons. The levels of brain serotonin are tightly controlled by various serotonin transporters. Both increased and decreased concentrations of brain serotonin levels show harmful effects. It is believed that in autistic patient's serotonin transporter may be altered; this could be one of the reasons for their irritability and repeated behavior [32]. In this study, ICV infusion of PPA produced an increased concentration of brain serotonin levels (in Group II rats) as compared with Group I rats. The extract treatment showed a reduction in the brain serotonin concentration.

Many researchers have reported that altered brain 5-HT system is there in ASD. Chugani et al. 1999 and Shoaf et al. 2000 carried out a surrogate measure to evaluate brain $5-\mathrm{HT}$ synthesis, which appears to follow a changed developmental pattern in autism [33, 34]. Many researchers were tried to find out the serotonin receptor or transporter binding and its association with ASD. By conducting the platelet binding studies and neuroimaging studies on children with autism, Goldberg et al. 2009 found a decreased 5-HT2 receptor binding in ASD [35]. A postmortem study conducted by Oblak et al. 2013 reported that there is a decrease in both 5-HT2A (5-Hydroxy tryptamine receptor 2 A) and 5-HT1A (5-Hydroxy tryptamine receptor $1 \mathrm{~A}$ ) binding in ASD patients [36]. Serotonin is one of the major neurotransmitters which regulate the mood, emotional stability, and sleep pattern of an individual. Serotonin also got major effects on blood vessels and small intestine. High levels 
of serotonin in blood and brain are considered as the first biomarker to identify ASD [37].

Glutamate is one of the chief excitatory signal conductors found in brain and spinal cord, as it got a leading role in brain development by affecting neuronal differentiation, migration, and synaptogenesis [38]. Scientific evidence also points out the glutamate involvement in general cognitive functions such as learning and memory [39]. However, excess levels of glutamate concentration act as a potent neurotoxin that leads to neuronal cell death [40]. Many research evidence showed that the ASD pathophysiology is greatly influenced by glutamatergic neurotransmission [41, 42]. The present study also justifies the above statement; here we can observe the high glutamate concentration of Group II animal brain when compared with Group I; EECT treatment reduced the glutamate concentration in a statistically significant manner.

Phytochemical evaluation of Clitoria ternatea $\mathrm{L}$. showed the presence of tannins, alkaloids, saponins, steroids, carbohydrate, protein, triterpenoids, and various poly phenols like anthocyanin and flavonoids [43]. Researchers have reported the ability of different poylphenols to modulate the metabolism or action of various neurotransmitters [44-46]. In the present study, the EECT produced significant neuroprotection against PPA-induced autism in rats; it may be due to various phytoconstituents present in it.

\section{Conclusions}

The present study findings showed that the ethanolic root extract of Clitoria ternatea L. possesses neuroprotective activity with significant nootropic effects. The effects are mainly produced by manipulating the levels of serotonin and glutamate in the autistic rat brain. Preliminary phytochemical analysis and HR LCMS (High-Resolution Liquid Chromatography-Mass Spectrometer) analysis of ethanolic root extract of Clitoria ternatea showed the presence of various anthocyanin and flavonoids polyphenol; these may be the reason for its neuroprotective and memory enhancement effects. However, further research should be carried out in Clitoria ternatea to isolate the possible phytoconstituents and evaluate the same to find out their actual mechanism for neuropharmacological effects.

\footnotetext{
Abbreviations

ASD: Autism spectrum disorders; CDC: Centre for Disease Control and Prevention; EECT: Ethanolic extract of Clitoria ternatea L.; P.O: Per oral; gm: Gram; cm: Centimeter; mg/kg: Milligram/kilogram; $\mu$ l: Microliter; ICV: Intracerebroventricular; PPA: Propionic acid; PBS: Phosphate-buffered saline; NOR: Novel object recognition; TL: Transfer latency; RL: Retention latency; ANOVA: Analysis of variance; SD: Standard deviation; 5-HT: 5-Hydroxy tryptamine.
}

\section{Acknowledgements}

This publication is a part of the Ph.D. thesis of The Tamil Nadu DR.M.G. R Medical University, Chennai, Tamil Nadu, India. The authors are very much thankful to the Department of Pharmacology, C.L.Baid Metha College of Pharmacy, Chennai, India, for research facilities and other logistic supports. Plant authentication approval: The fresh root of Clitoria ternatea $\mathrm{L}$. was collected from Kerala, India, and authentified by Botanist Prof.P.Jayaraman, Ph.D., Director, Plant Anatomy \& Research Centre, West Tambaram, Chennai. India. A voucher specimen (SES.CLBM.NO. 1458) is preserved at the Herbarium of Department of Pharmacognosy, C.L.Baid Metha College of Pharmacy, Chennai, India.

\section{Authors' contributions}

PM guided JKN in planning and designing the research. PM also helped in arranging the whole facilities for the research and supervised the whole research. JKN conducted the entire laboratory works imparted in study design and interpreted the results putting efforts into statistical analysis with the guidance of PM. PM and JKN participated in the manuscript draft and have thoroughly checked and revised the manuscript for necessary changes in format, grammar, and English standard. All authors read and agreed on the final version of the manuscript. The authors read and approved the final manuscript.

\section{Funding}

The part of the research work was funded by'Students welfare Section (University Research Council Grants)- The Tamil Nadu DR.M.G.R Medical University, Chennai, India,' during the year 2016-2018.

\section{Availability of data and materials}

The datasets used and/or analyzed during the current study are available from the corresponding author on reasonable request.

\section{Declarations}

\section{Ethics approval and consent to participate}

The study approved was approved by the Institutional Animal Ethical Committee of C.L. Baid Metha College of Pharmacy, Chennai, India. Approval No: IAEC/ XLIX/10/CLBMCP/2016.

\section{Consent for publication}

Not applicable.

\section{Competing interests}

Authors declared that they have no conflict of interest.

Received: 24 January 2021 Accepted: 9 August 2021

Published online: 21 August 2021

\section{References}

1. Gadad BS, Hewitson L, Young KA, German DC (2013) Neuropathology and Animal models of autism: genetic and environmental factors. Autism Res Treat 1-12. https://doi.org/10.1155/2013/731935

2. https://www.autismspeaks.org/science-news/cdc-increases-estimateautisms-prevalence-15-percent-1-59-children. Accessed on 27 Feb 2019

3. Onore C, Careaga M, Ashwood P (2012) The role of immune dysfunction in the pathophysiology of autism. Brain Behav Immun 26(3):383-392. https://doi.org/10.1016/j.bbi.2011.08.007

4. MacFabe DF, Rodriguez-Capote K, Hoffman JE, Franklin AE, MohammadAsef Y, Taylor AR, Boon F, Cain DP, Kavaliers M, Possmayer F, Ossenkopp K (2008) A novel rodent model of autism: intraventricular infusions of propionic acid increase locomotor activity and induce neuroinflammation and oxidative stress in discrete regions of adult rat brain. Am J Biochem Biotechnol 4(2):146-166. https://doi.org/10.3844/ajbbsp.2008.146.166

5. Williams JG, Higgins JP, Brayne CE (2006) Systematic review of prevalence studies of autism spectrum disorders. Arch Dis Child 91(1):8-15. https:// doi.org/10.1136/adc.2004.062083

6. Wing $L$ (1981) Language, social, and cognitive impairments in autism and severe mental retardation. J Autism Dev Disord 11(1):31-44. https://doi. org/10.1007/BF01531339 
7. Singh RH, Narsimhamurthy K, Singh G (2008) Neuronutrient impact of Ayurvedic Rasayana therapy in brain aging. Biogerontology 9:369-374. https://doi.org/10.1007/s10522-008-9185-z

8. Dash SC, Tripathi SN, Singh RH (1983) Clinical assessment of medhya drugs in the management of psychosis (unmada). Anc Sci Life 3(2):77-81

9. Rai KS, Murthy KD, Karantha KS, Rao MS (2001) Clitoria ternatea (Linn) root extract treatment during growth spurt period enhances learning and memory in rats. Indian J Physiol Pharmacol 45(3):305-313

10. Botham PA (2004) Acute systemic toxicity — prospects for tiered testing strategies. Toxicol In Vitro 18(2):227-230. https://doi.org/10.1016/s08872333(03)00143-7

11. Sarumathy K, Rajan MD, Vijay T, Jayakanthi J (2011) Evaluation of phytoconstituents, nephro-protective and antioxidant activities of Clitoria ternatea. J Appl Pharm Sci 1(05):164-172

12. Mirza R, Sharma B (2019) Beneficial effects of pioglitazone, a selective peroxisome proliferator-activated receptor- $\gamma$ agonist in prenatal valproic acid-induced behavioral and biochemical autistic like features in Wistar rats. Int J Dev Neurosci 76:6-16. https://doi.org/10.1016/j.ijdevneu.2019. 05.006

13. Samih MN, Belaaouja PK, Touhami SAO, Ahami AOT (2017) Effect of dimethoate on object recognition memory in wistar rats and essay of treatment with nettle. J Behav Brain Sci 7(9):425-445

14. Ennaceur A, Delacour J (1988) A new one-trial test for neurobiological studies of memory in rats 1: behavioral data. Behav Brain Res 31(1):47-59. https://doi.org/10.1016/0166-4328(88)90157-x

15. Sharma AC, Kulkarni SK (1992) Evaluation of learning and memory mechanisms employing elevated plus-maze in rats and mice. Prog Neuro-Psychopharmacol Biol Psychiatry 16(1):117-125. https://doi.org/ 10.1016/0278-5846(92)90014-6

16. Kraeuter AK, Guest PC, Sarnyai Z (2019) The elevated plus maze test for measuring anxiety-like behavior in rodents. Methods Mol Biol 1916:6974. https://doi.org/10.1007/978-1-4939-8994-2_4

17. Sandhya T, Sowjanya J, Veeresh B (2012) Bacopa monniera (L.) Wettst ameliorates behavioral alterations and oxidative markers in sodium valproate induced autism in rats. Neurochem Res 37(5):1121-31. doi: https://doi. org/10.1007/s11064-012-0717-1.

18. Dennis SC, Clark JB (1977) The pathway of glutamate metabolism in rat brain mitochondria. Biochem J 168(3):521-527. https://doi.org/10.1042/ bj1680521

19. Andres C (2002) Molecular genetics and animal models in autistic disorder. Brain Res Bull 57(1):109-119. https://doi.org/10.1016/s0361-9230(01) 00642-6

20. Thompson GN, Walter JH, Bresson JL, Ford GC, Lyonnet SL, Chalmers RA, Saudubray JM, Leonard JV, Halliday D (1990) Sources of propionate in inborn errors of propionate metabolism. Metabolism 39(11):1133-1137. https://doi.org/10.1016/0026-0495(90)90084-p

21. Kuijper EJ, Coignard B, Tüll P (2006) ESCMID Study Group for Clostridium difficile; EU Member States; European Centre for Disease Prevention and Control. Emergence of Clostridium difficile-associated disease in North America and Europe. Clin Microbiol Infect 6:2-18. https://doi.org/10. 1111/j.1469-0691.2006.01580.x

22. Jan G, Belzacq AS, Haouzi D, Rouault A, Métivier D, Kroemer G, Brenner C (2002) Propionibacteria induce apoptosis of colorectal carcinoma cells via short-chain fatty acids acting on mitochondria. Cell Death Differ 9(2):179-188. https://doi.org/10.1038/sj.cdd.4400935

23. Zárate G, González S, Chaia AP (2004) Assessing survival of dairy propionibacteria in gastrointestinal conditions and adherence to intestinal epithelia. Methods Mol Biol 268:423-432. https://doi.org/10.1385/1-59259-7661:423

24. MacFabe DF, Cain DP, Rodriguez-Capote K, Franklin AE, Hoffman JE, Boon F, Taylor AR, Kavaliers M, Ossenkopp KP (2007) Neurobiological effects of intraventricular propionic acid in rats: possible role of short chain fatty acids on the pathogenesis and characteristics of autism spectrum disorders. Behav Brain Res 176(1):149-169. https://doi.org/10.1016/j.bbr.2006. 07.025
25. Vargas DL, Nascimbene C, Krishnan C, Zimmerman AW, Pardo CA (2005) Neuroglial activation and neuroinflammation in the brain of patients with autism. Ann Neurol 57(1):67-81. https://doi.org/10.1002/ana.20315

26. Chauhan A, Chauhan V (2006) Oxidative stress in autism. Pathophysiology 13(3):171-181. https://doi.org/10.1016/j.pathophys.2006.05.007

27. Morales-Delgado N, Popović N, De la Cruz-Sánchez E, Caballero Bleda M, Popović M (2018) Time-of-day and age impact on memory in elevated plus-maze test in rats. Front Behav Neurosci 12:304. https://doi.org/10. 3389/fnbeh.2018.00304

28. Silvers JM, Harrod SB, Mactutus CF, Booze RM (2007) Automation of the novel object recognition task for use in adolescent rats. J Neurosci Methods 166(1):99-103. https://doi.org/10.1016/j.jneumeth.2007.06.032

29. Buckmaster CA, Eichenbaum H, Amaral DG, Suzuki WA, Rapp PR (2004) Entorhinal cortex lesions disrupt the relational organization of memory in monkeys. J Neurosci 24(44):9811-9825. https://doi.org/10.1523/JNEUR OSCI.1532-04.2004

30. Albasser MM, Davies M, Futter JE, Aggleton JP (2009) Magnitude of the object recognition deficit associated with perirhinal cortex damage in rats: effects of varying the lesion extent and the duration of the sample period. Behav Neurosci 23(1):115-124. https://doi.org/10.1037/a0013829

31. Hay-Schmidt A (2000) The evolution of the serotonergic nervous system. Proc Biol Sci 267(1448):1071-1079. https://doi.org/10.1098/rspb.2000. 1111

32. Welker C (1971) Microelectrode delineation of fine grain somatotopic organization of $(\mathrm{Sml})$ cerebral neocortex in albino rat. Brain Res 26(2):259-275

33. Chugani DC, Muzik O, Behen M, Rothermel R, Janisse JJ, Lee J, Chugani HT (1999) Developmental changes in brain serotonin synthesis capacity in autistic and nonautistic children. Ann Neurol 45:287-295

34. Shoaf SE, Carson RE, Hommer D, Williams WA, Higley JD, Schmall B, Herscovitch P, Eckelman WC, Linnoila M (2000) The suitability of [11C]-alphamethyl-L-tryptophan as a tracer for serotonin synthesis: studies with dual administration of [11C] and [14C] labeled tracer. J Cereb Blood Flow Metab 20:244-252. https://doi.org/10.1097/00004647-200002000-00004

35. Goldberg J, Anderson GM, Zwaigenbaum L, Hall GB, Nahmias C, Thompson A, Szatmari P (2009) Cortical serotonin type-2 receptor density in parents of children with autism spectrum disorders. J Autism Dev Disord 39:97-104

36. Oblak A, Gibbs TT, Blatt GJ (2013) Reduced serotonin receptor subtypes in a limbic and a neocortical region in autism. Autism Res 6:571-583

37. Muller CL, Anacker AMJ, Veenstra-VanderWeele J (2015) The serotonin system in autism spectrum disorder: from biomarker to animal models. Neuroscience 321:24-41. https://doi.org/10.1016/j.neuroscience.2015.11. 010

38. Lodge $D$ (2009) The history of the pharmacology and cloning of ionotropic glutamate receptors and the development of idiosyncratic nomenclature. Neuropharmacology 56(1):6-21. https://doi.org/10.1016/j. neuropharm.2008.08.006

39. Manent JB, Represa A (2007) Neurotransmitters and brain maturation: early paracrine actions of GABA and glutamate modulate neuronal migration. Neuroscientist 13(3):268-279. https://doi.org/10.1177/10738 58406298918

40. Nicoletti F, Bockaert J, Collingridge GL, Conn PJ, Ferraguti F, Schoepp DD, Pin JP (2011) Metabotropic glutamate receptors: from the workbench to the bedside. Neuropharmacology 60(7-8):1017-1041. https://doi.org/10. 1016/j.neuropharm.2010.10.022

41. Yang P, Chang CL (2014) Glutamate-mediated signaling and autism spectrum disorders: emerging treatment targets. Curr Pharm Des 20(32):5186-5193. https://doi.org/10.2174/13816128196661401101 20725

42. Ford TC (2017) Increased glutamate/GABA + ratio in a shared autistic and schizotypal trait phenotype termed social disorganisation. Neuroimage Clin 16:125-131. https://doi.org/10.1016/j.nicl.2017.07.009

43. Jiji KN, Muralidharan P (2020) Neuropharmacological potentIAL of Clitoria ternatea Linn.-a review. Res J Pharm Technol 3(11):5497-5502. https://doi. org/10.5958/0974-360X.2020.00960.9 
44. Lu CW, Lin TY, Wang SJ (2013) Quercetin inhibits depolarization-evoked glutamate release in nerve terminals from rat cerebral cortex. Neurotoxicology 39:1-9. https://doi.org/10.1016/j.neuro.2013.07.009

45. Wang R, Xu Y, Wu HL, Li YB, Li YH, Guo JB, Li XJ (2008) The antidepressant effects of curcumin in the forced swimming test involve 5-HT1 and 5-HT2 receptors. Eur J Pharmacol 578(1):43-50. https://doi.org/10.1016/j.ejphar. 2007.08.045

46. Rebas E, Rzajew J, Radzik T, Zylinska L (2020) Neuroprotective polyphenols: a modulatory action on neurotransmitter pathways. Curr
Neuropharmacol 18(5):431-445. https://doi.org/10.2174/1570159X18 666200106155127

\section{Publisher's Note}

Springer Nature remains neutral with regard to jurisdictional claims in published maps and institutional affiliations.

\section{Submit your manuscript to a SpringerOpen ${ }^{\circ}$ journal and benefit from:}

- Convenient online submission

- Rigorous peer review

- Open access: articles freely available online

- High visibility within the field

Retaining the copyright to your article

Submit your next manuscript at $\boldsymbol{\nabla}$ springeropen.com 